\title{
EL ESTADO MEXICANO Y LA 4T: PERENNE BÚSQUEDA DEL CAUDILLO
}

\author{
Édgar G. Hernández H. ${ }^{1}$
}

La propuesta del nuevo gobierno mexicano encabezado por el presidente Andrés Manuel López Obrador en materia de seguridad pública y procuración de justicia, ha sido delineada con elementos de política criminal y criminológica que nos hacen reflexionar desde la dimensión de la academia, que los planteamientos gubernamentales de la autodenominada Cuarta Transformación (4T), se encuentran entre lo que Max Weber identificaba como el dilema entre la ética de la responsabilidad y la ética de la convicción, esto es, entre la necesidad gubernamental de responder a las demandas sociales de seguridad y paz social con un profundo espíritu pragmático, y el paradójico discurso del respeto a la dignidad humana y los derechos humanos como fuente de legitimidad de la acción política.

Al triunfo el primero de julio de 2018 de la opción política representada por el partido político Movimiento de Regeneración Nacional (MORENA), y de los cientos de candidatos a diversos puestos de elección popular en todo el país, encabezados por el hoy presidente de la república Andrés Manuel López Obrador, comenzó una cuenta atrás de la expectativa que llevó a 30 millones de mexicanos a decidir un viraje al modelo político y económico vigente en nuestro país desde hace 30 años.

1 El presente trabajo se presentó en el marco del III Congreso Internacional de derecho, organizado por la Facultad de Derecho y Ciencias Políticas del Corporación Universitaria del Caribe, del 9 al 14 de octubre de 2018, en Sincelejo, Colombia. El autor es académico de la Universidad Autónoma de Tlaxcala, ex director de Comunicación Social y Relaciones Públicas de la misma casa de estudios, editor de libros y ensayista en diferentes medios de información sobre cuestiones de derechos humanos, historia, antropología y tecnologías de la información y la comunicación. 
Edgar G. Hernández H.

Con una inédita mayoría legislativa tanto en la Cámara Alta como en la Cámara Baja, y con el triunfo en gran parte de los Congresos de las entidades federativas y otros cargos de elección popular (gubernatura de la Ciudad de México, en Veracruz, así como alcaldías en esas y otros estados del país), el régimen presidencialista encabezado por López Obrador tiene la histórica alternativa de cambiar el destino de la nación hacia lo que él mismo ha denominado la Cuarta Transformación (4T).

\section{E1 preámbulo del viraje político-electoral}

Múltiples han sido las explicaciones que se han dado para tratar de explicar el viraje político que dio el pueblo mexicano en el proceso electoral de 2018, para decidir en una suerte de golpe de timón, cambiar las condiciones del panorama político, sobre todo si consideramos el cierto conservadurismo político que manifestó durante los últimos 30 años la ciudadanía mexicana, aunado al manejo clientelar que se hacía de las minorías votantes que sostenían el status quo de los grupos gobernantes. Pareciese que el desinterés del gran elector silencioso — esa mayoría de votantes que se abstuvieron por considerar de poco sentido manifestarse en las urnasera el estado de ánimo perfecto para el otro gran elector representado en la figura del presidente en su calidad de fiel de la balanza.

Y los efectos de ese incuestionable presidencialismo, se podían adivinar: la víspera de la contienda electoral de 2018, los intereses de la clase política gobernante, de los grupos de oposición y de la sociedad civil organizada, se vieron orientados hacia decisiones que ponían a dudar a unos sobre otros respecto de la legitimidad de esas decisiones.

En 2018 se colocó en juego la continuidad de una serie de políticas públicas que iniciaron en el sexenio de Enrique Peña Nieto, y cuyas raíces se encuentran atadas a compromisos de orden político-económico de tal magnitud, que hicieron necesaria la unción de un candidato que además de tecnócrata, viniese presuntamente de la propia ciudadanía, es decir, un candidato no priista, un candidato no surgido de las entrañas contradictorias del priismo en un inicio revolucionario, después nacionalista, y hoy de marcados trazos neoliberales. 
Del lado opositor, se consolidaron candidaturas que ya no respondieron a las ideologías de los partidos, sino al más estricto interés del pragmatismo político, y en esa condición, las facciones opositoras se unieron en dos grandes bloques que se registraron como coaliciones, que hacen dudar a más de un elector sobre las tendencias o plataformas electorales que se entremezclan y confunden sobre la base de la necesidad de ganar.

En medio de todas estas posiciones políticas que se disputaron el ejercicio del poder, se colocaron las legítimas demandas de la sociedad - en una nueva oportunidad donde habría de replantearse de nueva cuenta el futuro del país-, y entre una de las más importantes, se encontró indudablemente el tema de la seguridad pública.

Y si bien no es interés de este documento abordar a detalle las causas de la derrota de los partidos políticos que habían detentado posiciones de poder sustantivas en años recientes (como el Partido Acción Nacional, el Partido de la Revolución Democrática, y por supuesto, el Partido Revolucionario Institucional, PAN, PRD y PRI, respectivamente), sí podemos afirmar cinco aspectos básicos que, desde nuestra visión, explican en cierto modo la percepción de la ciudadanía respecto de estos institutos políticos, entre los cuales se encuentra, por supuesto, la cuestión de la criminalidad y su escasa contención por parte de las instituciones del Estado mexicano.

- Una política económica dedicada en los últimos 18 años a la satisfacción de ciertas franjas de la élite mexicana;

- Una política social que no alcanzó a cubrir con puntualidad las demandas sociales, lo que aceleró el número de personas pobre en el país, colocándolas en un número aproximado de 60 millones;

- Un resquebrajamiento de los pactos al interior de la clase política tradicional, que implicó el aglutinamiento alrededor de la opción representada por MORENA, de una parte significativa de los cuadros institucionales, corporativos y empresariales (léase sindicatos, agrupaciones sociales, cúpulas industriales, grupos religiosos), cuadros funcionales a los regímenes conservadores panistas y priistas; 
Edgar G. Hernández H.

- Una desmesurada práctica de la corrupción a todos los niveles y en gran parte de los espacios gubernamentales, resultado de un modelo de connivencias entre entes corruptores y entes corrompidos, que hizo insostenible la viabilidad del proyecto transexenal representado en los candidatos José Antonio Meade Kuribeña (PRI) y Ricardo Anaya Cortés (PAN-PRD y otros), y

- Un desolador escenario de criminalidad organizada donde la insuficiencia del trabajo de los operadores policiacos y de procuración y administración de justicia, junto con la complicidad de políticos de diversos colores partidistas con los grupos delincuenciales, colocaron en un estado de orfandad a la ciudadanía en cada uno de los 31 estados y Ciudad de México, con una escandalosa cifra de delitos estimada anualmente en alrededor de 30 millones, de acuerdo a la Encuesta Nacional de Victimización y Percepción sobre Seguridad Pública 2018 (ENVIPE, 2018).

Así, se ha llamado la atención en ponderar nuestro escenario jurídico para replantear las responsabilidades del Estado, sobre todo en el combate a la corrupción y la impunidad. El planteamiento de las experiencias análogas siempre se ha identificado como un ejercicio epistemológico que nos da la posibilidad de confrontar nuestros avances como individuos y como colectividad; esto significa que no podemos darnos cuenta de nuestra realidad si no la confrontamos con otras realidades, otras dimensiones, otras cosmogonías.

$\mathrm{Y}$ en eso se ha fincado el nuevo régimen: en observar lo realizado por anteriores administraciones, para tratar de enmendar cuentas no a los personajes políticos, sino a la estructura roída por las humedades de la corrupción.

\section{Rezago en materia convencional}

$\mathrm{Y}$ es que debemos admitir una realidad: México, ha quedado rezagado en su realidad jurídica con respecto a varias naciones del cono sudamericano, como ocurre con Argentina, Uruguay, Chile, Perú o Colombia. 
Para nosotros, temas como la afirmación constitucional de los derechos humanos — con todo lo que ello implica desde la dogmática jurídica-, o la plena integración de nuestro país al Sistema Interamericano de Derechos Humanos (SIDH), y la consecuente aceptación de la jurisdicción de la Corte Interamericana de Derechos Humanos (Corte-IDH), entre otras situaciones relacionadas con la temática de los derechos humanos, son asuntos de relativa novedad en nuestro orden jurídico doméstico, lo que de ninguna manera constituye algo de lo que debamos tener orgullo.

Comprender el devenir jurídico de esta experiencia jurídico política en México, requiere asomarnos a un proceso histórico-revisionista que integre el análisis de las formas en como el poder político en nuestra república ha venido configurándose desde etapas decimonónicas, entrelazando reflexiones de orden filosófico, antropológico, y por supuesto, sociológico.

Somos un país que para todas sus soluciones, como civilización, siempre estamos a la expectativa de la llegada de un caudillo.

\section{En la búsqueda de un caudillo}

Desde que la conquista española nos quitó en 1521 y en los años posteriores la esperanza de contemplar el regreso del mítico dios-hombre escandinavo Quetzalcóatl, hemos buscado en los caudillos la luz que nos lleve a la utopía del venturoso porvenir, esa utopía de la que nos habla Carlos Fuentes en su Espejo enterrado.

Así, después de concretar la independencia en 1821 de las manos del decadente imperio hispánico, nos desgastamos en luchas intestinas entre conservadores y liberales, dejando el paso a las veleidades de un militar que se puso los ropajes de caudillo y emperador, como lo fue el criollo Agustín de Iturbide, y la Constitución de 1824 a cuestas. Después, este disfraz fue usado por Antonio López de Santa Anna, que en sus múltiples administraciones al frente del país, no contemplaba ser emperador, pero sí deseaba que se lo honrara con el título de Su Alteza Serenísima, y bajo cuyo mandato vimos perder medio territorio nacional en 1847 a 
Edgar G. Hernández H.

manos de las cada vez más hambrientas fauces del incipiente y belicoso poderío estadunidense.

Más tarde, con la nueva Constitución en 1857, habríamos de procurar con el caudillo indígena conocido universalmente como el Benemérito de las Américas, don Benito Juárez García, recuperar nuestra libertad de las manos de los acreedores europeos, con quienes ya comenzábamos a relacionarnos de modo draconiano.

Sin embargo, las contradicciones propias de nuestra clase política, nos llevaron a apostar por el regreso de otro emperador extranjero que emulase al Moctezuma precolombino y al Iturbide independentista: hablo de Maximiliano de Habsburgo, cuya aventura imperial no duró más allá de los tres años que el propio Juárez le permitió al ajusticiarlo en la emblemática ciudad de Querétaro en 1867.

En las postrimerías del siglo XIX, decidimos integrarnos al positivismo emergente, guiados por el caudillo militar Porfirio Díaz, a quien habrían de suceder otros cabecillas intermitentes que llegaron al acuerdo constitucional con la Carta Magna de 1917, y con ello para acabar con celadas y traiciones, se institucionalizó el poder político en la figura del presidencialismo exacerbado, alimentado por el corporativismo clásico que devino en dos institutos políticos omnipotentes, decantando finalmente en el hoy vilipendiado Partido Revolucionario Institucional, derrotado por uno de los últimos caudillos que pretende un viraje sustantivo para los intereses nacionales: Andrés Manuel López Obrador.

Este recuento de caudillismos, no es exclusivo de México, y Colombia lo sabe, como también lo sabe Venezuela, y allende la cordillera del sur, lo saben Perú, Chile y Argentina, que experimentaron los utópicos caudillismos de Simón Bolívar y José de San Martín, por mencionar a los más significativos del siglo XIX.

Es así que a partir de este caudillismo presidencial, México vivió durante todo el siglo XX aislado jurídicamente del Sistema Interamericano de Derechos Humanos, cobijado en las ramas de la doctrina Estrada, instaurada en México desde los años 30's de ese siglo, y que se explica en la autodeterminación y en la no intervención, es decir, México toleraba la autodeterminación de cualquier país, siempre y cuando no se cuestionara, como decía el nobel de literatura Octavio Paz, al ogro filantrópico mexi- 
cano, representado por esa figura paternalista gubernamental que trataba a su sociedad con violencia y benevolencia, con despotismo y bondad, en una tóxica relación que derivó en un agudo régimen de libertades ficticias, sin posibilidades de ser ejercidas.

Es así que los regímenes mexicanos navegaron sobre la base de una autodeterminación sin cortapisa, con todo lo bueno y malo de ese esquema de ejercicio del poder político. Entre 1960 y el año 2000, era impensable el cuestionamiento formal de la Corte Interamericana de Derechos Humanos hacia el gobierno mexicano, porque nosotros no admitíamos la jurisprudencia de la Corte.

Y hoy toda política criminal que no advierta la inserción de los derechos humanos en su entramado jurídico, no puede ser tomada como formalmente válida por la preponderancia del garantismo y los derechos humanos.

$\mathrm{Y}$ en ese rezago, las violaciones a derechos humanos desde los estamentos de la política criminal, negaron cualquier orden internacional. Vamos, incluso la Convención Americana sobre Derechos Humanos, fue ratificada y adherida por México 12 años después de su adopción en el marco de la Organización de los Estados Americanos (OEA), y la competencia de la Corte Interamericana de Derechos Humanos, la admitimos hasta 1998, lo que indudablemente nos colocaba en un lugar poco decoroso en cuanto al avance y evolución de la protección y defensa de la dignidad humana.

¿Y por qué nos negábamos a aceptar la competencia y posterior jurisdicción del Sistema Interamericano de Derechos Humanos?

Dice el connotado jurista Sergio García Ramírez, que las circunstancias históricas en que se ha formó la política internacional de México, generó la necesidad de recurrir a principios firmes como reducto de presiones injustas, así como la falta de medios para enfrentar a las codicias externas con el poder de la fuerza o la riqueza", aunque también es cierto que García Ramírez y quienes coinciden con él ( $v$ gr. Enrique Krauze), nos presenta una visión que favorece al conservadurismo mexicano, y por ende, al sistema político y los beneficiarios del mismo. 
Edgar G. Hernández H.

\section{El fin de los Estados nacionales}

Pero el tiempo del proteccionismo político se nos agotó. Los procesos globalizadores y del neoliberalismo surgidos del Consenso de Washington de los años ochenta, junto con la caída del ideal comunista soviético y con ello el fin de las ideologías, como lo interpretara Francis Fukuyama, colocó a los Estados nacionales en una situación sumamente frágil y cuestionable. Quizá esta sea una de las pocas ventajas de la globalización, esta apertura hacia nuevos escenarios jurídicos, a través de lo que en la doctrina se denomina la "irradiación de los órdenes normativos continentales hacia los órdenes normativos domésticos".

Ese periodo coincide con el resquebrajamiento del régimen presidencialista en México, a partir del acceso al poder ejecutivo de otras opciones partidistas en 2000 y 2006, y ahora, en 2018. No existe ya esa "doctrina Estrada": la vieja clase política mexicana y sus herederos debieron abrir sus lóbregos sótanos de impunidad y permitir el sojuzgamiento de los órganos jurisdiccionales regionales como la Corte Interamericana.

Un ejemplo de esto lo significa el emblemático caso de Rosendo Radilla Pacheco, luchador social de los años 70's del siglo pasado, que fue "desaparecido" por fuerzas castrenses en la sierra de Guerrero, y del que no se supo más sino hasta luego de un tortuoso proceso de poco más de treinta años, donde la Corte Interamericana (previo paso por la Comisión Interamericana de Derechos Humanos), dictó sentencia condenando al gobierno mexicano el 23 de noviembre de 2009, de donde se deriva que es necesario que las interpretaciones constitucionales y legislativas referidas a los criterios de competencia material y personal de la jurisdicción militar en México (tema de controversia en este caso), se adecuen a los principios establecidos en la jurisprudencia de la Corte Interamericana que han sido reiterados en el caso en comento, y que aplican para toda violación de derechos humanos que se alegue hayan cometido miembros de las fuerzas armadas.

Pero además, la Suprema Corte de Justicia de la Nación, en el paradigmático expediente Varios 912/2010, derivado de la señalada sentencia, acuerda la aplicación material de la jurisdicción de la Corte Interamericana de Derechos Humanos, así como la obligación para quienes imparten justicia de inaplicar las normas contrarias a la Constitución y a los 
tratados internacionales en materia de derechos humanos, y a ordenar la realización del control difuso de convencionalidad por parte de todos los jueces del país.

Pero estos procesos de apertura jurídica, no son producto de una serie de graciosas concesiones del Estado mexicano: aquellas, como ocurre con otras políticas de la nación, responden a las presiones internacionales, como ocurre con la reforma constitucional de 2001 en materia de la reserva del principio de dignidad humana, contenida en el artículo primero último párrafo, que refiere la prohibición a toda discriminación motivada por origen étnico o nacional, el género, la edad, las discapacidades, la condición social, las condiciones de salud, la religión, las opiniones, las preferencias sexuales, el estado civil o cualquier otra que atente contra la dignidad humana y tenga por objeto anular o menoscabar los derechos y libertades de las personas.

Parece que sólo hasta ese momento, en los albores del nuevo siglo, nos dimos cuenta que existían los indígenas, las personas con discapacidad, las de la tercera edad, la comunidad LGTBI...

Después, en 2008, asumimos el reto de modificar nuestro sistema de seguridad pública y justicia, en función de dar vigencia al debido proceso con el recambio de paradigma, para transitar del sistema inquisitivo al sistema acusatorio, con juicio oral incluido, experiencia en la cual países del cono sur nos llevan ya bastante ventaja. La asunción de ese modelo no la adquirimos porque un día nos levantamos inspirados en recuperar el tiempo: asumimos ese modelo por las presiones de USAID, la Agencia de los Estados Unidos para el Desarrollo Internacional, apéndice del Departamento de Estado norteamericano.

Y más tarde, en 2011, admitimos las recomendaciones de la Oficina del Alto Comisionado de las Naciones Unidas para los Derechos Humanos, para integrar, a través de la reforma constitucional de junio de ese año, el catálogo universal de los derechos humanos a nuestra Carta Fundamental.

Es así que, como podemos ver una de las razones sustantivas de la continuidad en las políticas criminales de la 4T en el Estado mexicano, donde su apertura a los cambios de orden jurídico, ha transitado por 
Edgar G. Hernández H.

resistencias y objeciones políticas de cara a las exigencias de los gobernados.

Por eso, no bastan estas políticas criminales como referente de la autoridad del Estado, porque cuando desde hace 40 años se habla en el mundo del Estado constitucional de derecho como referente del garantismo y los derechos humanos, en México todavía estamos anclados en el caduco modelo del Estado de derecho.

Como sabemos, el modelo del Estado constitucional de derecho, se contrapone, de acuerdo a los juristas Serafín Ortiz y Raymundo Gil, al Estado de derecho de carácter legalista, positivista y formalista.

A diferencia del Estado de derecho, el Estado constitucional de derecho — nacido de la segunda posguerra europea teniendo como referente la Constitución de Bonn de 1949, la Constitución portuguesa de 1976, y Carta fundamental española de 1978 - justiprecia el contenido axiológico del derecho, es decir, los principios constitucionales se sobreponen al reduccionismo de la ley secundaria, a la codificación de los derechos subjetivos. Por ello, hablar de derechos humanos, es hablar de la ampliación de las potestades de las personas ante el órgano estatal, cosa poco cómoda para los operadores gubernamentales.

Es entonces el Estado constitucional de derecho el espacio natural y adecuado del garantismo, del neo-constitucionalismo y de la dignidad humana, factores que, sin embargo, también confrontan los afanes de las sociedades de la posmodernidad, que por un lado promueven la extensión de sus derechos, pero por el otro, exigen mayor severidad contra los crimina les, más allá de sus derechos fundamentales, y esa paradoja social la han sabido capitalizar facciones políticas qua e han triunfado en los últimos años en varias naciones de nuestro continente. Estamos en el tiempo del denuesto y la apología de los derechos humanos, y esta contradicción coloca en riesgo nuestros tenues avances en este escenario, contradicción motivada por tres aspectos:

1) La renuencia de las viejas generaciones de operadores estatales a dejar de lado las visiones legalistas de la estructura del Estado de derecho. 
2) La falta de experticia y compromiso de las generaciones vigentes con los cambios adjetivos que se generan y

3) Los altos índices de reproducción del crimen e impunidad ante el mismo que se vive en México.

La nación se debate en este tiempo en esa contradicción que mencionamos, sobre todo cuando, en una población de 115 millones de habitantes promedio, existen desde hace seis años, registros de las entidades gubernamentales que contabilizan cantidades de delitos del orden común y federal, que no bajan de la espantosa cantidad de entre más de 20 y 25 millones de víctimas en promedio, con un número estimado entre $27 \mathrm{y}$ más de 33 millones de ilícitos, de los cuales, como todos sabemos, se investigan un porcentaje de menos del 5 por ciento, y se sancionan, si acaso, el uno por ciento de los mismos.

Y parece que no existe una salida coherente, lógica y sistemática, más que la del palo por palo, la violencia como lenguaje de los contendientes, y en medio de ellos, la sociedad desprotegida.

Veremos qué nos sugiere, materializa y concluye la 4T de Andrés Manuel López Obrador. 